\title{
Beyond space and time-Conceiving the rhythmic configurations of adult education through Lefebvre's rhythmanalysis
}

\author{
Michel Alhadeff-Jones $(\mathbb{D}$
}

Received: 28 December 2018 / Accepted: 12 April 2019 / Published online: 30 April 2019

(C) The Author(s) 2019

\begin{abstract}
Like a fabric made of different threads, adult education waives multiple places and reveals different paces whose influences may be complementary, contradictory and antagonistic with each other. The spaces and times that shape people's life are rarely static or constant. They evolve and fluctuate. Every day, throughout their existence, people have to learn to adjust, coordinate and move through material, natural, social and symbolic environments that keep evolving. The aim of this paper is to explore how to conceive the influences of both spatial and temporal configurations through which adults learn, transform and develop themselves. To proceed, the reflection refers to Henri Lefebvre's contribution, and more specifically to his conception of rhythmanalysis. The paper first introduces Lefebvre's ideas around space and time, and opens up the possibility to conceive their relations through the concept of rhythm. Then, the idea of rhythmanalysis is introduced and its use in educational research discussed. The third part of the paper explores and illustrates more specifically three concepts introduced by Lefebvre to interpret the relations between rhythmic phenomena (arrhythmia, polyrhythmia and eurhythmia). It is finally suggested that this triple lens opens up the possibility to analyze the relations between space, time and educational processes through three prototypical rhythmic configurations found in the practice: the experiences of dissonance, alternance and resonance.
\end{abstract}

Keywords Space $\cdot$ Time $\cdot$ Rhythm $\cdot$ Rhythmanalysis $\cdot$ Adult education

M. Alhadeff-Jones

Teachers College, Columbia University, New York, USA

Institut Sunkhronos, Geneva, Switzerland

E-Mail: maj@sunkhronos.org 


\section{Jenseits von Raum und Zeit - Annäherungen an rhythmische Konfigurationen der Erwachsenenbildung mit Lefebvres Rhythmusanalyse}

Zusammenfassung Wie ein Stoff aus verschiedenen Fäden gewebt ist, so ist die Erwachsenenbildung auf vielfältigste Weise auf Räumlichkeiten bezogen und offenbart unterschiedlichste Tempi. Dabei beeinflussen sich diese Dimensionen gegenseitig, und zwar indem sie sich ergänzen, widersprechen oder Gegensätze bilden. Die Räume und Zeiten, die das Leben der Menschen prägen, sind selten statisch oder konstant. Sie entwickeln und verändern sich. Täglich müssen Menschen lernen, sich anzupassen, sich zu koordinieren und sich durch gegenständliche, naturgegebene, soziale und symbolische Umgebungen zu bewegen, die sich ihrerseits beständig weiterentwickeln. Ziel dieses Beitrags ist es, die Einflüsse räumlicher und zeitlicher Konfigurationen, durch die Erwachsene lernen, zu verstehen und zu entwickeln. Dabei beziehen sich die Überlegungen auf Henri Lefebvres Ideen zu Raum, Zeit und Rhythmus. Dabei wird sein Ansatz einer Rhythmusanalyse vorgestellt und deren Verwendung für die Erwachsenenbildung bzw. in der Bildungsforschung diskutiert. Im dritten Teil der Arbeit werden drei von Lefebvre eingeführte Konzepte zur Interpretation der Beziehungen zwischen rhythmischen Phänomenen (Arrhythmie, Polyrhythmie und Eurhythmie) näher beleuchtet. Abschließend wird vorgeschlagen, mit Blick auf diese drei Phänomene die Beziehungen zwischen Raum, Zeit und Bildungsprozessen anhand von drei in der Praxis vorgefundenen prototypischen rhythmischen Konfigurationen zu analysieren: den Erfahrungen von Dissonanz, Alternanz und Resonanz.

Schlüsselwörter Raum $\cdot$ Zeit $\cdot$ Rhythmus $\cdot$ Rhythmusanalyse $\cdot$ Bildung

\section{Space, time and their influences on educational processes}

When I started working at the University of Geneva in 2000-before the implementation of the Bologna policy-courses were still provided on a yearly basis over a period of eight months. At that time, I was facilitating life history seminars in order to bring students to reflect on the specificities of adult education, based on their own autobiographical experience (Dominicé, 2007). In 2004, when I moved to New York City and designed my first life history seminar with graduate students at Teachers College, Columbia University, I had to adjust a process that used to be facilitated over 30 sessions to fit within a five-week period. It required me to divide the number of class hours by two. The compression-some would call it an acceleration-not only concerned the amount of time spent with students; it also affected the frequency of our encounters and the learning process that was occurring between each session. Such an experience triggered in me a conflict inherent to the tensions between the temporal standards that were defining my practice in higher education in Switzerland and the temporal constraints that characterized the academic environment I was getting accustomed to. This experience triggered many interrogations regarding what could or could not be done in such a setting. As a practitioner, they 
led me to question how to conceive the transposition of a specific learning process between two places, held within different institutions, located in different countries, and grounded in heterogeneous cultures, characterized among others by different ways to relate to time. As a researcher, they brought me to question how to study the influence of space and time on learning processes implemented in a formal context, and beyond, on educational dynamics experienced by adults throughout their lives.

Teaching in multiple institutions, located in different countries, or experimenting with heterogeneous educational designs eventually bring any educator to realize that the influence of a specific environment goes beyond what can be reduced to numbers or standards, such as those discussed in chronometric conceptions of education (e.g. instructional time, academic learning time). Moreover, grasping the complexity of educational processes requires more than what prescriptive approaches may provide (e.g. accelerated learning, slow education) (Alhadeff-Jones 2017). The complexity of educational processes is shaped by many variables, both objective and subjective, that determine how learning and changes occur through heterogeneous spaces and times. What is at stake is to determine how to identify, interpret and evaluate the relations through which space and time influence educational processes, including the way they are lived subjectively. Recent developments in educational research have shown the significance of considering changes taking place in the policy, practice, and study of education, considering the way people perceive, conceive and experience space and time. Both indeed represent critical lenses to describe and interpret phenomena through which autonomy, identity and inequalities are produced in society (e.g., Alhadeff-Jones 2017; Bright et al. 2013; Ferrare and Apple 2010; Gulson and Symes 2007; Lesourd 2006; Pineau 2000; Usher 2002). Focusing on the situatedness of educational processes raises questions about how people (e.g. learners, educators, policy makers) determine the meaning, the relevance and the value associated with specific environments, in relation to learning, transformational or developmental processes, as they may be lived, desired or expected.

\section{Space, time and Lefebvre's idea of rhythmanalysis}

Based on previous research (Alhadeff-Jones 2017) and privileging a theoretical approach, the aim of this paper is to explore how the complexity of the relations that exist between space, time and the experience of educational processes may be conceived. To proceed, two main issues have to be addressed. The first one is to establish how the experience of space and time can be envisioned as a whole, in a way that is relevant to learners and educators. The second one is to provide a conceptual lens to interpret the relations between the experience of a spatio-temporal environment and the activities constitutive of educational processes themselves. To address those two issues, this paper explores the contribution of Henri Lefebvre (1901-1991), a French philosopher and sociologist, known for his thinking on rural and urban life forms, his interest in Marxist critique and the sociology of everyday life, and his writings on rhythmanalysis, a method dedicated to the study of lived rhythms. Lefebvre's approach demonstrates in particular the value and the impor- 
tance of studying rhythms, as a way to describe, interpret and eventually influence the processes through which adults may develop their autonomy and sustain their agency in different contexts and environments throughout their life (Alhadeff-Jones 2017). Lefebvre's contribution on rhythmanalysis is indeed an 'attempt to get us both to think space and time differently, and to think them together' (Elden 2004, p. ix).

Accordingly, the reflection developed in this paper starts by briefly introducing Lefebvre's ideas around space and time, referring in particular to The Production of Space (Lefebvre 1991 [1974]) and Rhythmanalysis (Lefebvre 2004 [1992]). Considered as part of the same project, those two books - among others-open up the possibility to conceive the relations between space and time through the concept of rhythm. In order to conceive the relations between the experience of rhythms and educational processes, the idea of rhythmanalysis is introduced and its use in educational research briefly discussed. The following section of the paper explores and illustrates more specifically three concepts introduced by Lefebvre to interpret the relations between rhythmic phenomena (arrhythmia, polyrhythmia and eurhythmia). It is then suggested that this triple lens opens up the possibility to analyse the relations between space, time and educational processes through three prototypical rhythmic configurations found in practice: the experiences of rhythmic dissonance, alternance and resonance. The article concludes with considerations regarding the development of a rhythmanalytical approach in adult education and the research agenda it opens up.

\section{Lefebvre's conception of space and time}

In order to understand Lefebvre's conception of space and time, it is at first necessary to break with the widespread understanding of space and time, imagined as phenomena existing 'in themselves'. As it is now commonly accepted in social sciences, both space and time have to be understood as social constructs that have their own historicity. For Lefebvre, space and time are produced, based on the way people relate to each other and to their environment. They are both result and precondition of the production of society: 'Accordingly, space and time do not exist universally. As they are socially produced, they can only be understood in the context of a specific society. In this sense, space and time are not only relational but fundamentally historical. This calls for an analysis that would include the social constellations, power relations, and conflicts relevant in each situation.' (Schmid 2008, p. 29) At the same time, it is critical to acknowledge with Lefebvre the fact that space and time are also bound to physical, biological, psychological, socio-cultural or spiritual phenomena that cannot be reduced to the social meanings attached to them. Accordingly, the study of space and time as they relate to human experiences should not be envisioned in isolation from research conducted in other disciplines (AlhadeffJones 2017; Lefebvre 2004 [1992]). 


\subsection{The production of space}

As a social product, space can be analysed in relation to three dimensions: (1) the interlinking network of activities or interactions which rest upon a determinate material basis (e.g. built environment); (2) the linguistic representations that serve as a frame of reference for communication and orientation (e.g. verbal descriptions); and (3) the meanings and symbols conveyed by the materiality of space, and the norms, values and experiences they carry (e.g. the feeling of safety, danger or power associated with a specific place) (Schmid 2008, p. 37). From a phenomenological perspective, the three dimensions of the production of space can be accessed through the interactions between the 'perceived' (perçu), the 'conceived' (conçu) and the 'lived' (vécu) (Lefebvre 1991 [1974]). Thus, the materiality of space can be grasped by the senses, including seeing, hearing, smelling, touching and tasting. To be perceived, space also has to be conceived as a whole in thought; its conception relies on the production of knowledge. Finally, space is lived through the experiences that human beings have in their everyday life (Schmid 2008, pp. 39-40). Accordingly, space is determined by the interplay between material production, the production of knowledge and the production of meaning. Space is therefore neither static nor a given; it is actively produced and reproduced through an intricate web, made of perceptions, knowledge and experiences. As it is continuously shaped by active processes, space has to be conceived through its reproduction or its metamorphosis as these processes unfold through time, that is, through both everyday life and human history.

\subsection{Space, time and embodiment}

For Lefebvre, understanding the complex relations between space and time requires one to take into consideration the central role played by human corporeality and sensuousness. Whether on their own, through relationships with others, or through their interactions with the environment, people feel, imagine and experience space and time through their body. For Lefebvre (1991 [1974], p. 405), '[t]he whole of (social) space proceeds from the body ...' For instance, organized (i.e. ritualized or codified) gestures are not simply performed in physical space, they also contribute to generating spaces produced by and for those gestures. Thus, cloisters are designed in accordance with the solemn pace of the monks who walk there (Lefebvre 1991 [1974], p. 216). In the same way, schools are conceived around specific spaces (e.g. separated classrooms, hallways, stairways, playground, gym) where dedicated activities unfold, spontaneously or according to routines. According to Lefebvre (1991 [1974] p. 216), '[w] hen a gestural space comes into conjunction with a conception of the world possessed of its own symbolic system, a grand creation may result.' Thus, the gestural space of cloisters may contribute to the mooring of a mental space of contemplation and theological abstraction, expressed symbolically, at the same time that it becomes part of a dedicated social practice. Similarly, instructional places, such as schools or universities, may be conceived as favouring the emergence, day after day, of mental spaces associated with specific knowledge and meanings. 


\section{Interpreting the relations between space and time through the lens of rhythms}

Lefebvre (2004 [1992], p. 15) argues that '[e]verywhere where there is interaction between a place, a time and an expenditure of energy, there is a rhythm.' In the 1960s, he started conceiving the notion of rhythm as a way to study everyday activities and the way they unfold through space and time (e.g. Lefebvre 2002 [1961], 1991 [1974], 2004 [1992]). His interest in rhythms was part of a broader concern regarding the quotidian, the banality and the emptiness of everyday life within capitalist society. Because all human practices are constituted in terms of a relationship between repetition and difference (Lefebvre 2004 [1992]), they provide grounds to study everyday interactions based on the rhythms they display, including in educational settings (e.g. Christie 2013; Hopwood 2013; Jacklin 2004; Middleton 2013). Assuming that social space and time (e.g. urban city, school, informal environment) produce, and are produced through, the experience of repetition and variation, Lefebvre conceived quotidian spaces (e.g. streets, working spaces, classrooms) as the result of activities (e.g. walking, moving, writing, talking, listening) whose rhythmic features could become the focus of analysis (Revol 2014).

\subsection{Lefebvre's rhythmanalysis}

At first, Lefebvre envisioned the analysis of rhythms as a sociological method to study the fabric of relations and interactions between social temporalities found in industrial society, such as those determined by cyclic rhythms (e.g. alternance between day and night) and linear processes (e.g. monotonous repetitions of assembly lines) (Revol 2014). The critical aim of rhythmanalysis came therefore from the possibility to unveil how social practices (e.g. work, education, consumption, art) may be experienced as alienating or liberating, depending on their rhythmic qualities and the way they are shaped by social spaces and times. As stressed by Elden (2004, p. xii), Lefebvre, in Rhythmanalysis, '... uses rhythm as a mode of analysis-a tool of analysis rather than just an object of it - to examine and re-examine a range of topics.' Inspired by Bachelard's (1950) initial use of the idea of rhythmanalysis, Lefebvre's thought evolved to take the concept of rhythm and turn it into a 'science, a new field of knowledge: the analysis of rhythms; with practical consequences' (Lefebvre 2004 [1992], p. 3). Thus, Lefebvre conceived rhythmanalysis as an embodied approach through which the 'rhythmanalyst' has to feel and to experiment empirically how rhythms are lived. Such a practice requires one to 'listen' to one's body as a 'metronome' and to 'learn rhythm from it' to appreciate external rhythms (Lefebvre 2004 [1992], p. 19). Focusing on one's senses, breath, heartbeats and rhythmic use of one's limbs is required to feel and perceive lived temporalities and to apprehend how they relate to the temporal and spatial environment within which one evolves. It is a work of appropriation of one's own body as much as it may lead to the transformation of social praxis (Revol 2014), based on the conscious regulation of external rhythmic influences. 


\subsection{Rhythmanalysis and educational research}

The rhythmic qualities of educational praxis and the significance of the concept of rhythm in educational discourses have evolved throughout history (Alhadeff-Jones 2017). From Plato's musical education (Republic) to rhythmic approaches developed in the early twentieth century (e.g. Jaques-Dalcroze, 1921; Bode, 1920/2014; Mandelstam, 1920/1979; Steiner, 1920/1995, as cited in Alhadeff-Jones 2017), references to rhythmic pedagogies have mostly relied on analogies and metaphors in order to interpret and justify their educational effects on the body, the psyche and society as a whole (Alhadeff-Jones 2017). Since the 1980s, developments in chronobiology and chronopsychology have demonstrated the importance of considering biological and psychological rhythms as factors impacting the quality of learning (Sue and Rondel 2001). Such contributions have influenced educational policies and the design of curricula to take into consideration both the heterogeneity of students (including their biological and psychological rhythms) and the decompartmentalization of the spatial and temporal structures through which they were taken in charge (e.g. Fotinos and Testu 1996; Husti 1999; Sue and Rondel 2001) in order to make them less rigid. In comparison with all those approaches, Lefebvre's contribution fills a gap: by inscribing the experience of individual rhythms within the history of social spaces, and by showing how such spaces relate to the intimate experience of time (e.g. repetitive, discontinuous), Lefebvre's rhythmanalysis provides educators with a concrete path—and a medium — to critically envision how individual and collective rhythms may relate to each other, how they are inscribed in power dynamics, and how such relations are institutionalized within a society (Alhadeff-Jones 2017).

The influence of Lefebvre's rhythmanalysis on educational research remains modest. In English-speaking countries, interest in Lefebvre's contribution on rhythmanalysis has started to emerge (e.g. Christie 2013; Dakka and Wade 2019; Hopwood 2013; Jacklin 2004; Mathisen 2015, 2016; Middleton 2013; Wozniak 2017), benefitting from the recent translation of his work. Studying pedagogic practice in schools, Jacklin (2004) demonstrates for instance how repetition and differences are regulated in the space and time of classroom practice, leading to a more or less 'arid pedagogic experience' that impacts learners' achievement. In the context of South African schools, Christie (2013) discusses how the production of space enables flows, rhythms and sequences of activities to be explored at global, national and local scales, with a view to understanding the multiple rhythms that produce educational inequalities. Hopwood's (2013) ethnographic study of parenting education and pedagogic practices in a child and family service explores the intricate connections between rhythm and adult learning, including rhythms as content and processes at the heart of parenting education. Dakka and Wade's (2018) research on academic writing makes a case for the use of rhythmanalysis as a diagnostic method capable of signalling the increasing disjunction between the institutional demands of accelerated production and the slower, irrational rhythms of craftsmanship in higher education.

In France, Pineau (e.g. 1986, 2000) and Hess (e.g. 2006, 2009) were among the first in adult education to introduce theoretical reflections informed by Bachelard and Lefebvre's contributions to rhythmanalysis. Pineau's (2000) landmark book, 
Temporalités en Formation, is probably the very first attempt to develop a theory of adult education organized around the concept of rhythm, suggesting the idea of 'chronoformation' (later relabeled 'rhythmoformation') as a figure of emancipatory education. Hess (e.g. 2006, 2009) explores strategies through which a subject may become more conscious of the whole rhythmic dynamics that organize the spaces and times of one's life. Pineau's and Hess's contributions have inspired a new generation of scholars, mainly in adult and higher education (Alhadeff-Jones 2017; Galvani 2004; Lesourd 2009; Roquet 2018). Their interpretations of rhythmanalytical work - through their efforts to question the strategies implemented and the resources required for adults to build up the capacity to extract themselves from moments embedded in specific spaces and times experienced as alienating-promise to facilitate transitions or to create new liberating opportunities. Such contributions therefore question the relationship between rhythmic awareness, the dynamics of self-development and emancipatory education (Alhadeff-Jones 2017).

\section{Applying a rhythmanalytical lens to the praxis of adult education}

As promising as it may be, referring to the idea of rhythmanalysis still requires the development of a theoretical and conceptual apparatus privileging a rhythmological and process-oriented approach to adult education (Alhadeff-Jones 2017, 2018). One of the many possibilities provided by Lefebvre's contribution to analysing the rhythmical dimensions constitutive of social phenomena is to refer to the distinction he establishes between four concepts: polyrhythmia, eurhythmia, arrhythmia and isorhythmia. Polyrhythmia refers to phenomena that are composed of diverse rhythms. Eurhythmia presupposes the association of different rhythms; for instance, it characterizes the organization of a living and healthy body. In arrhythmia, 'rhythms break apart, alter and bypass synchronisation ...' (Lefebvre 2004 [1992], p. 67). Isorhythmia completes this repertoire of fundamental concepts. It designates an equality or a full equivalence between rhythms. Isorhythmia and eurhythmia are mutually exclusive. 'There are few isorhythmias, rhythmic equalities or equivalences, except of a higher order. On the other hand, eurhythmias abound: every time there is an organism, organization, life (living bodies).' (Lefebvre 2004 [1992], p. 67) To Lefebvre, '[r]hythmanalysis therefore essentially consists in the forming of these concepts into a work (which can change them, transform them) ...' (Lefebvre 2004 [1992], p. 68) Moreover, he claims that '[i]ntervention through rhythm ... has a goal, an objective: to strengthen or re-establish eurhythmia' (Lefebvre 2004 [1992], p. 68). In the context of adult education, such a general claim deserves to be developed and nuanced. To proceed, the following sections explore more specifically the concepts of arrhythmia, polyrhythmia and eurhythmia to describe how they may help to analyse the influence that the experience of space and time has on learning and development. 


\subsection{Arrhythmia and the experience of rhythmic dissonance}

Arrhythmia is characterized by the provisional or permanent lack of synchronization between rhythms. It may refer to a broad range of phenomena from physiological symptoms (e.g. cardiac arrhythmia), psychological states (e.g. mood disorder) to organizational dysfunctions (e.g. lack of coordination within a collectivity). Subjectively, it may be perceived, represented or lived as a feeling of incongruence and disconnection, a lack of harmony or a disagreement that expresses dissonance. At a low level of intensity, arrhythmia is usual when traveling long distance. The mismatch between one's biological rhythms synchronized with a specific place and time, and the different conditions at arrival (i.e. jet-lag) makes one feel out-of-sync. At a higher level, rhythmic dissonances involve more radical differences. In adult education, they may be experienced in or between formal, non-formal and informal settings. They occur whenever and wherever people are confronted with phenomena that display asynchronous patterns, frequencies or periods of activity that appear disconnected and eventually irreconcilable with each other.

Considering adults' self-development and lifelong learning processes, rhythmic dissonances may be, for instance, associated with the experience of 'double belonging', a notion used by Dominicé (2007) to characterize the personal tensions inherent in the divide between complementary and antagonistic aspects of one's life: family versus working life; social background versus professional environment; urban life versus rural roots; et cetera. Those dimensions of one's life unfold through different spaces and evolve through changes that display various rhythms. Therefore, whenever they appear as too divergent from each other, they may be experienced as fragmented and out-of-sync. This phenomenon reinforces a feeling of being split between caring and being productive, the history of one's family and one's own current path, the rhythms that characterize the places where one comes from versus those where one lives, and so on. The lack of congruence between concomitant facets of one's life, as they may be experienced or reflected through different spaces and times, represents a significant source of dissonance that may limit one's sense of agency. Privileging a temporal lens, Pineau (2000) proposed the neologism 'schizochrony' (from the Greek schizo-, meaning divide, and chronos, time) to refer to the various forms of temporal divide that emerge between different spheres of one's life (e.g. family time versus professional time) or between inner and outer worlds (e.g. biological rhythms versus social rhythms). Such divides may eventually lead individuals to feel alienation.

On the one hand, arrhythmia and rhythmic dissonance, as conceived through experiences of double belonging or schizochrony, may be lived as a source of disorientation, confusion or even helplessness. They may confront people with ambivalent, contradictory and conflicting aspects of their everyday life. If left unresolved, such experiences may interfere with learning and further development, as they may consume people's energy, desires and motivations. On the other hand, such disorienting situations may also trigger learning and transformative processes (Mezirow 1991), as they may stimulate the need to adjust or adapt—oneself or one's surrounding—in order to solve the lived feeling of incongruence, disconnection or lack of harmony. 


\subsection{Polyrhythmia and the experience of rhythmic alternance}

Polyrhythmia is found in environments where heterogeneous rhythms co-exist simultaneously without being coordinated with each other. Ecosystems, companies, schools or classrooms exemplify polyrhythmia, as they involve a broad range of simultaneous activities or behaviours that are not systematically synchronized, without necessarily being in conflict with each other. In the absence of synchronization, one has to focus on each of them separately, and eventually successively, in order to grasp their own specific rhythms. The term 'alternance' suggests such a movement, as it refers to the phenomenon of alternation, which is required to grasp different phenomena successively. Rhythmic alternance refers therefore to a specific way to coordinate and sustain one's awareness of polyrhythmic phenomena (e.g. settings, behaviours, discourses, interactions) that are recognized and acknowledged as being heterogeneous.

Considering institutionalized forms of adult education, the experience of rhythmic alternance is typically constitutive of dual education, as it is organized around distinct spaces and temporalities through which learners evolve alternatively (e.g. workplace and productive time; classroom and study time). Distinguishing different forms of dual education, Bourgeon (1979, p. 36) defines, for instance, two modalities of alternance (juxtapositive and associative), based on the qualities of the relations that are established between productive activity and vocational training. Juxtapositive alternance refers to situations where there is no organized link between workplace and school. Learning strategies that may foster the integration of knowledge among learners are typically neglected. Associative alternance is found whenever the educational system (e.g. vocational school, university) acknowledges the role played by professional practice, and participants' agency is taken into consideration. It requires both an appropriate temporal organization and the basic adjustment between the provision of and demand for training (Pineau 2000, p. 157). The possibilities of coordinated encounters between different partners (e.g. students, mentors and internship supervisors) opens up a network of relationships that minimizes the risk of dissonance, although it does not recognize the singularity of each learner's needs.

Through the examples of juxtapositive and associative alternances, polyrhythmia appears as a basic configuration for learning and development. Like a melody articulates a succession of notes, polyrhythmia and rhythmic alternance rely on the capacity to synchronize 'horizontally' a succession of moments (e.g. work and study) whose heterogeneous rhythms carry formative effects. In dual education, what is at stake is the capacity to establish distinctions and connections between experiences, knowledge and skills acquired in different environments in order to foster the development of transversal competencies. More broadly, the educational potential inherent to rhythmic alternance relies on the capacity to articulate the benefits of evolving through heterogeneous spaces and times so that they can be related through images, narratives or curricula that provide subjects with a sense of coherence. However, if the capacity to coordinate and organize rhythmic alternance is missing, or if polyrhythmia cannot be sustained over time, the risk of dissonance emerges. 


\subsection{Eurhythmia and the experience of rhythmic resonance}

The idea of eurhythmia evokes a feeling of harmony. As for polyrhythmia, it involves a form of rhythmic coordination. However, such an organization relies specifically on the capacity to synchronize 'vertically' rhythms that relate to each other simultaneously. Eurhythmia is at the core of how healthy organisms (e.g. human body, ecosystem) sustain themselves. In a social context, it may involve different layers, more or less tangible, including discourses (e.g. shared norms, rhythms of elocution, flow of thought, speaking slots), embodiment (e.g. movement, non-verbal communication) or social interactions (e.g. the ebb and flow of an exchange). Eurhythmia evokes an experience of resonance, as it may involve the reinforcement and the amplification of rhythmic phenomena within a specific space and time. In the physical world, amplification may result from a transfer of vibration or energy (e.g. sound, tidal motion, electromagnetic field). In social interactions, it results from the power of evoking or suggesting images, memories, feelings and emotions that contribute to a corresponding or sympathetic response. From an educational perspective, referring to the idea of resonance involves environments that affect the way people perceive, feel, think and give meanings to their experiences in order to sustain and reinforce specific learning phenomena.

In his research on dual education, Bourgeon (1979, p. 37, my translation) describes a third kind of educational opportunities characterized by an 'effective compenetration of the socio-professional and school environments within a formative temporal unit.' In what Bourgeon designates as a 'copulative' setting, the influence of the vocational school and the work environment is limited to the establishment of the formal training, the definition of the learning objectives and the organization of certifying assessment. The learning strategies and the articulation between work and study remain for the most part regulated between the partners themselves, as individuals, networks or groups (Geay 1999). The privileged temporality is no longer the polyrhythmic temporal framework of the institution (e.g. official schedules and calendars) as it is the case with juxtapositive and associative alternances. It is rather the one produced by the persons who participate in the training, through their synchronized actions. Such a system privileges therefore the time of auto-formation (Pineau 2000, p. 157), as it provides the involved learners with more autonomy to create and organize their own learning environment in coherence with the pace of their own activity. Resonance emerges through the self-organization of mutual coordination. Considering informal dynamics, such as those emerging from interpersonal relations (e.g. mentoring) or in small group dynamics (e.g. work unit), phenomena of resonance can also be observed whenever the subjects find ways to synchronize the rhythms of their activity (e.g. speech, emotional display, non-verbal behaviours) in order to develop new behaviours (e.g. enhanced intimacy, mutual understanding) or a shared capacity to reach specific goals (e.g. coordinated actions, team building).

From an educational perspective, eurhythmia and the experience of rhythmic resonance require the capacity to produce a shared space and time that leads to the amplification or the emergence of specific feelings, behaviours, or thoughts. What is at stake is the capacity to create an environment that stimulates the merging of rhythms into a cohesive whole, like playing different notes at the same time pro- 
duces a pleasing harmony. The educational value of such resonance comes with the new dispositions and behaviours that such a process of entrainment may produce. However, because of the close proximity and the feeling of flow they sustain, eurhythmia and resonance also make it more difficult to find the distance and the otherness required in order to feel, assess or analyse the situation within which they occur.

\subsection{Analysing rhythmic dissonance, alternance and resonance in adult education}

Arrhythmia, polyrhythmia and eurhythmia represent three distinct ways to express how the experience of space and time may interact with educational processes. Thus, the identification of rhythmic dissonance, alternance, and resonance provides learners, practitioners and researchers with three notions to describe how learning, change or developmental dynamics may be lived through space and time. The significance of those notions comes from what they may reveal: the presence of antagonisms and complementarities among phenomena that are observed or lived. Such antagonisms and complementarities express underlying aspects that may be analysed in order to better understand the influence that an environment has on educational processes. To illustrate this point, it seems relevant to consider the conflicting experience I described in the introduction to this article, referring to the transposition of a specific learning process (i.e. a life history seminar) between two places (Geneva and New York City), held at different institutions (a public university and an Ivy League college) located in different countries, and grounded in heterogeneous cultures, characterized among others by different ways to relate to time.

In this case, I first experienced rhythmic dissonance through organizational aspects, such as academic calendars and course schedules, which differed from one place to another. It revealed features that characterize how the activity of an institution is regulated in a specific place (e.g. country, city, school) and at a specific time of its history. Questioning the experience of rhythmic dissonance also led to highlight conflicting views about the way time is taken into consideration within the institution. Thus, the implementation of this life history seminar involved at least three temporal logics that were constitutive of the polyrhythmic configuration encountered: (a) the time required for this specific training method to unfold, based on its content, the learners involved and the group dynamics; (b) the time formally allocated, based on programme and scheduling requirements; and (c) the temporal constraints exercised by the external environment (e.g. professional environments where students worked in parallel to their studies, family), expressing competing pressures and expectations regarding the participants' availability. Because it problematizes such a configuration, the subjective experience of rhythmic dissonance brings out the possibility to analyse and argue about the values, norms and choices involved in the educational setting.

When considering the learning process itself, a methodology such as the one implemented in life history seminars relies on a variety of activities (e.g. lecture, introspection, self-reflection, reading, writing, dialoguing among peers) that are characterized by the repetition through space and time of specific patterns of 
actions. Such repetitions reveal specific rhythms that may trigger experiences of dissonance, alternance or resonance, depending on the way the activities are implemented (e.g. course design), regulated (e.g. instructor's facilitation) and invested (e.g. participants' engagement). For instance, the relation between the time available for participants to engage in dialogue, the material conditions of their encounter (e.g. arrangement of tables and chairs, virtual meeting), the nature of the communication that has to be implemented (e.g. dialogue based on personal disclosure), and participants' own motivations may or may not lead to an experience of rhythmic resonance amplifying the learning dynamics. When I first taught at Teachers College, although I was anticipating a feeling of dissonance due to the short time available to establish a trustful group dynamic, the opposite happened. A feeling of resonance emerged between the 'rapid' introduction of exercises involving self-disclosure, as required by the compressed schedule, and the temporal expectations of the participants regarding classroom interactions. As an 'outsider', the situation revealed for me two features inherent to that environment that were taken for granted by the participants: a cultural one (shared norms among them regarding how interpersonal communication may unfold through time) and an economic one (shared expectations regarding the use of their time in the classroom and the duration of their stay in the city, influenced by the financial costs of their studies and local accommodations).

As briefly illustrated above, paying attention to rhythmic dissonance, alternance and resonance opens up the possibility to read critically the antagonisms, the tensions, the conflicts of interests, as well as the complementarities, the cohesion and the affinities that shape an educational setting. Such observations may become a matter of learning too, whenever they are made explicit and become a topic of reflection. Since I started reflecting on such dynamics, I have chosen to systematically discuss with the participants of my courses the rhythms involved and how specific tasks may or may not be implemented. Such an approach appears as a powerful trigger to bring participants to critically reflect on the spatio-temporal configurations that shape their learning and to analyse the everyday praxis of adult education.

\section{Synthesis}

To Lefebvre, space determines, as much as it is determined by, the interplay between material elements, representations and meanings. It is actively produced and reproduced through an ongoing flow of perceptions, knowledge and experiences, influenced by the way people interact with their environment. Such a process unfolds through time; the time of everyday life and the time of personal and collective history. Time in itself cannot be observed. It can however be felt, conceived and lived through the experience of changes and the rhythms they involve. Analysing rhythms, therefore, appears to be a meaningful way to reveal the qualities associated with specific spaces and the way they influence one's development over time. As a method, rhythmanalysis suggests that we pay attention to rhythms and more specifically to the relations between rhythms. Following Lefebvre's intuition, it seems particularly relevant to consider the influence that space and time have on educational phenomena through three kinds of rhythmic configuration: arrhythmia, polyrhythmia 
and eurhythmia. Evolving through heterogeneous spaces or temporalities that appear disconnected may confront learners or professionals in education with a feeling of rhythmic dissonance inherent to arrhythmia. Such a situation may interfere with learning and development, as much as it may trigger transformative processes. Being confronted with a plurality of rhythms that co-exist without conflicting with each other (polyrhythmia) may lead people engaged in educational processes to experience rhythmic alternance; a process through which one may learn to articulate and coordinate different spaces and times that carry specific educational opportunities. Finally, experiencing rhythmic resonance, a state characterized by the synchronization of different rhythms into a cohesive whole (eurhythmia) may contribute to the emergence of new dispositions and behaviours. At the same time, it may also make it more difficult for the people involved to find the distance required to question the way they relate to the situation in which they are immersed. Those three prototypical experiences illustrate how rhythmic phenomena are intertwined and mediate the relations between the heterogeneous spaces and times that shape any educational processes.

\section{Opening}

Education does not occur through a single space or time. Like a fabric made of different threads, it waives multiples places (e.g. home, school, work, art spaces, urban and natural environments) and reveals different paces (e.g. family habits, school routines, working schedules, institutional calendars, seasonal changes). Furthermore, the places and paces that shape people's life are rarely static or constant. They evolve and fluctuate. Thus, every day, throughout their existence, people have to learn to adjust, coordinate and move through environments that keep evolving. Such a movement is constitutive of who we are, as much as it defines how we evolve and what we become, personally and professionally. From an educational perspective, it raises many questions. How to identify spatial and temporal configurations that may reinforce meaningful learning experiences? What are the resources required to be able to regulate the influence that heterogeneous spaces and times have on learning, transformational and developmental processes? How to negotiate conflicts that may occur whenever the experience of space and time is lived as a source of tensions?

A rhythmanalytical approach does not provide straight answers to such questions. Its contribution relies first on the capacity to challenge the assumptions based on which the relations between space, time and educational processes are conceived. Thus, the adoption of a rhythmanalytical approach suggests that we explore not only the functional effects that specific spaces and temporalities have on learning, transformation and development (how do they constrain people's activity) but also their symbolic influences (how do they impact people's representations). The second contribution of a rhythmanalytical approach is that it stresses the importance of considering rhythms as a critical source of information about the qualities of an educational process. The adoption of a rhythmanalytical sensibility requires one to learn to discriminate, interpret, examine, argue, judge and eventually challenge 
the relations between rhythms that are experienced and the environment in which they are lived or observed. Such a critical capacity cannot be taken for granted. Its development, therefore, requires further research in order to establish how such a sensibility may be trained and applied in educational settings.

Rhythmanalysis does not only consider the experience of rhythms as a source of information. It also conceives it as locus of action and influence. Whether attention is paid to the rhythms of discourses, those that are embodied, or the rhythms that shape how people or institutions interact with each other, they all display patterns and repetitions that can be changed, organized or regulated to foster specific experiences. Rhythms express not only a medium through which people relate to space and time, it is also the medium through which power and agency is exerted (Michon 2005). When it is applied, rhythmanalysis therefore provides the opportunity for a performative process to unfold; a process through which people involved may identify and eventually regulate the influences that discourses, activities or interactions have on educational processes. Analysing the experience of arrhythmia, polyrhythmia and eurhythmia is a first step towards implementing a rhythmanalytical approach in adult education. Because the experience of rhythmic dissonance, alternance and resonance manifests as much as it determines how people learn, transform and develop themselves, it may serve as a critical entry point for learners, educators and their respective communities to influence educational processes. Their contribution may be envisioned from at least two angles. On the one hand, they may develop strategies to increase the positive effects associated with rhythmic dissonance, alternance and resonance: respectively, to trigger change, to coordinate the exposure to situations characterized by heterogeneous rhythms, and to amplify the emergence of new dispositions and behaviours. On the other hand, they may also develop strategies to decrease the negative influences of such rhythmic configurations: respectively, to experience incongruence and disconnection, lack of coherence and dispersion, or to be unable to take critical distance. Here again, such educational strategies cannot be taken for granted, and further research and experimentations have to be conducted to better understand what they involve. Lefebvre's intuitions on rhythmanalysis, therefore, open up a new space and time for learners, practitioners and scholars to develop the perceptive skills, meanings, knowledge and know-how required to better understand and influence the relations between space, time, educational processes and the power dynamics they involve.

Open Access This article is distributed under the terms of the Creative Commons Attribution 4.0 International License (http://creativecommons.org/licenses/by/4.0/), which permits unrestricted use, distribution, and reproduction in any medium, provided you give appropriate credit to the original author(s) and the source, provide a link to the Creative Commons license, and indicate if changes were made. 


\section{References}

Alhadeff-Jones, M. (2017). Time and the rhythms of emancipatory education. Rethinking the temporal complexity of self and society. London: Routledge.

Alhadeff-Jones, M. (2018). Pour une approche rythmologique de la formation. Education Permanente, 217, 21-31.

Bachelard, G. (1950). La dialectique de la durée. Paris: Presses Universitaires de France.

Bourgeon, G. (1979). Socio-pédagogie de l'alternance. Paris: UNMFREO.

Bright, N. G., Manchester, H., \& Allendyke, S. (2013). Space, place, and social justice in education. Qualitative Inquiry, 19(10), 747-755.

Christie, P. (2013). Space, place, and social justice: developing a rhythmanalysis of education in South Africa. Qualitative Inquiry, 19(10), 775-785.

Dakka, F., \& Wade, A. (2019). Writing time: a rhythmic analysis of contemporary academic writing. Higher Education Research \& Development, 38(1), 185-197.

Dominicé, P. (2007). La formation biographique. Paris: L'Harmattan.

Elden, S. (2004). Rhythmanalysis: an introduction. In H. Lefebvre (Ed.), Rhythmanalysis: space, time and everyday life (pp. vii-xv). London: Continuum.

Ferrare, J. J., \& Apple, M. W. (2010). Spatializing critical education: Progress and cautions. Critical Studies in Education, 51(2), 209-221.

Fotinos, G., \& Testu, F. (1996). Aménager le temps scolaire: Théories et pratiques. Paris: Hachette.

Galvani, P. (2004). L'exploration des moments intenses et du sens personnel des pratiques professionnelles. Interaction, 8(2), 95-121.

Geay, A. (1999). Actualité de l'alternance (note de synthèse). Revue Française de Pédagogie, 128, 107-125.

Gulson, K. N., \& Symes, C. (2007). Knowing one's place: space, theory, education. Critical Studies in Education, 48(1), 97-110.

Hess, R. (2006). Rythmanalyse et théorie des moments. Pratiques de Formation/Analyses, 51-52, 127-149.

Hess, R. (2009). Henri Lefebvre et la pensée du possible: Théorie des moments et construction de la personne. Paris: Economica.

Hopwood, N. (2013). The rhythms of pedagogy: an ethnographic study of parenting education practices. Studies in Continuing Education, 36(2), 115-131.

Husti, A. (1999). La dynamique du temps scolaire. Paris: Hachette.

Jacklin, H. (2004). Discourse, interaction and spatial rhythms: locating pedagogic practice in a material world. Pedagogy, Culture \& Society, 12(3), 373-398.

Lefebvre, H. (1991). The production of space. Malden: Blackwell. Original work published 1974

Lefebvre, H. (2002). Critique of everyday life. Vol. 2. London: Verso. Original work published 1961

Lefebvre, H. (2004). Rhythmanalysis: Space, time and everyday life. London: Continuum. Original work published 1992

Lesourd, F. (2006). Des temporalités éducatives: Note de synthèse. Pratiques de Formation / Analyses, $51-52,9-72$.

Lesourd, F. (2009). L'homme en transition: Education et tournants de vie. Paris: Edition economica anthropos.

Mathisen, A. (2015). Rhythms in education and the art of life: Lefebvre, Whitehead and Steiner on the art of bringing rhythmical transformations into teaching and learning-Part I. Research on Steiner Education, 6(2), 36-51.

Mathisen, A. (2016). Rhythms as a pedagogy of becoming: Lefebvre, Whitehead and Steiner on the art of bringing rhythmical transformations into teaching and learning-Part II. Research on Steiner Education, 6(2), 52-67.

Mezirow, J. (1991). Transformative dimensions of adult learning. San Francisco: Jossey-Bass.

Michon, P. (2005). Rythmes, pouvoir, mondialisation. Paris: Presses Universitaires de France.

Middleton, S. (2013). Henri Lefebvre and education: space, history, theory. London: Routledge.

Pineau, G. (1986). Time and lifelong education. In P. Lengrand (Ed.), Areas of learning basic to lifelong education (pp. 95-120). Oxford, Hamburg: UNESCO Institute for Education, Pergamon Press.

Pineau, G. (2000). Temporalités en formation. Paris: Anthropos.

Revol, C. (2014). La rythmanalyse lefebvrienne des temps et espaces sociaux, ébauche d'une pratique rythmanalytique aux visées esthétiques et éthiques. http://rhuthmos.eu/spip.php?article1102. Accessed 12 Oct 2015.

Roquet, P. (Hrsg.) (2018). Rythmes et temporalités en formation. Education Permanente, 217. 
Schmid, C. (2008). The production of space. Towards a three-dimensional dialectic. In K. Goonewardena, S. Kipfer, R. Milgrom \& C. C. Schmid (Eds.), Space, difference, everyday life. Reading Henri Lefebvre (pp. 27-45). London: Routledge.

Sue, R., \& Rondel, Y. (2001). Rythmes de vie et éducation. Les Cahiers Millénaire, 3(24), 25-53.

Usher, R. (2002). Putting space back on the map: globalisation, place and identity. Educational Philosophy and Theory, 34(1), 41-55.

Wozniak, J. T. (2017). Towards a rhythmanalysis of debt dressage: education as rhythmic resistance in everyday indebted life. Policy Futures in Education, 15(4), 495-508.

Publisher's Note Springer Nature remains neutral with regard to jurisdictional claims in published maps and institutional affiliations. 